Didáctica. Lengua y literatura

ISSN: 1130-0531

http://dx.doi.org/10.5209/DIDA.57132

\title{
La Literatura Infantil en la pintura prerrafaelita: claves iconográficas para la didáctica de los cuentos en el aula
}

\author{
Angélica García-Manso ${ }^{1}$
}

Recibido: 13 de marzo de 2017 / Aceptado: 28 de abril de 2017

Resumen. La Literatura constituye una de las fuentes de inspiración más importantes para los pintores prerrafaelitas, quienes, aparte de los relatos mitológicos y leyendas medievales, se sintieron también atraídos por la Literatura Infantil. De hecho, artistas de la talla de Edward Burne-Jones o John Everett Millais, por citar tan solo dos, plasmaron en sus lienzos a las protagonistas de Cenicienta, Blancanieves y La bella durmiente, entre otras. Se analizan las claves iconográficas presentes en estos cuadros con una doble finalidad didáctica: de un lado, utilizarlas como recurso visual para la enseñanza/aprendizaje de las distintas versiones de los cuentos de hadas; de otro, y desde una perspectiva más hermenéutica, desentrañar la omnipresencia de la representación femenina en dichas telas, de lo que se derivan importantes conexiones con la actual revisión de los mensajes implícitos en los relatos infantiles.

Palabras clave: Literatura Infantil y Juvenil, cuentos de hadas, pintura prerrafaelita, iconografía, discurso femenino.

\section{[en] Children's Literature In Pre-Raphaelite Painting: Iconographic Keys For Teaching Fairy Tales In The Classroom}

\begin{abstract}
Literature is one of the most important sources of inspiration for pre-Raphaelite painters, who, apart from mythological stories and medieval legends, also felt attracted by Children's Literature. In fact, artists as prominent as Edward Burne-Jones or John Everett Millais, to name just two, portrayed in their canvases the protagonists of Cinderella, Snow White and Sleeping Beauty, among others. The iconographic keys present in these pictures are analyzed with a double didactic purpose: on the one hand, to use them as visual resources for teaching / learning different versions of fairy tales; on the other, and from a more hermeneutic perspective, to unravel the omnipresence of female representation in these fabrics, which have important connections with the current revision of implicit messages in children's stories.
\end{abstract}

Key words: Children's Literature, fairy tales, pre-Raphaelite painting, iconography, feminist discourse.

\section{[fr] Littérature d'enfance et de jeunesse dans le préraphaélisme: clés iconographiques pour la didactique des contes de fées á la salle de cours}

Résumé. La littérature est l'une des sources les plus importantes d'inspiration pour les peintres préraphaélites, qui, en dehors des légendes médiévales et des histoires mythologiques, se sentait attiré par

\footnotetext{
Departamento de Didáctica de las Ciencias Sociales, de las Lenguas y las Literaturas

Facultad de Formación del Profesorado

Universidad de Extremadura

angmanso@unex.es
} 
la littérature d'enfance et de jeunesse. En fait, artistes de premier plan comme Edward Burne-Jones ou John Everett Millais, pour ne citer que deux, ont interprété dans leurs toiles les protagonistes de Cendrillon, Blanche-Neige et La belle au bois dormant, entre autres. Les clés iconographiques présent dans ces tableaux sont analysés avec un objectif à double didactique: d'une part, de les utiliser comme ressources visuelles pour l'enseignement / apprentissage des différentes versions de contes de fées; de l'autre, et dans une perspective plus herméneutique, de démêler l'omniprésence de la représentation féminine dans ces tableaux, qui ont des liens importants avec l'examen actuel des messages implicites dans les contes pour enfants.

Mots-clé: Littérature d'enfance et de jeunesse, contes de fées, préraphaélisme, iconographie, discours féminist.

Sumario: 1.Introducción. 2. La Cenicienta. 3. Blancanieves. 4. La Bella Durmiente. 5. Otros textos de Literatura Infantil en la pintura prerrafaelita. 6. Conclusión, o de cómo las distintas versiones de los cuentos infantiles confluyen en la lectura feminista finisecular. 7. Bibliografía.

Cómo citar: García-Manso, A. (2017). La Literatura Infantil en la pintura prerrafaelita: claves iconográficas para la didáctica de los cuentos en el aula. Didáctica. Lengua y literatura, 29, 2017, 103-119.

\section{Introducción}

Si hay un rasgo que define a los prerrafaelitas es el de ser unos pintores apasionados por la Literatura, que revisitan leyendas y mitos antiguos. De hecho, sus fuentes de inspiración son explícitamente literarias: las obras teatrales de Shakespeare (como en el caso de Ofelia-1852-, de John Everett Millais); los poemas góticos de Keats (Isabella -1849- o La víspera de Santa Inés -1863-, también de Millais, por citar solo un par de ejemplos), y los poemas medievales y artúricos de Tennyson ( $L a$ dama de Shalott -1888- o Mariana -1897-, ambos de John William Waterhouse, entre otros muchos) $)^{2}$.

Las correspondencias interartísticas en estos pintores llegan hasta el punto de que el texto poético puede irrumpir incluso en el espacio mismo del lienzo, como sucede en numerosas obras de Rossetti, poeta él mismo, sobre todo en la Venus Verticordia (1888). Parece oportuno señalar que su hermana, Christina Rossetti, fue una de las poetisas británicas más importantes del siglo XIX, y destacó especialmente en el ámbito de la literatura infantil (Dedebas, 2011). Y es que, como afirma Charlotte Ribeyrol, "[...] Estos cuadros reflejan un deseo de circulación creativa del poema al cuadro y del cuadro al poema" $(2014,33)$.

En este contexto, no es de extrañar que los prerrafaelitas volvieran también su mirada hacia la Literatura Infantil, en concreto, hacia los cuentos de hadas y, sobre todo, a sus protagonistas femeninas. Debe tenerse en cuenta que la literatura para niños vive su particular "siglo de oro" en el XIX, especialmente en Gran Bretaña. Entre los cuentos de hadas abordados por estos artistas sobresalen tres grandes ciclos: el de Cenicienta, el de Blancanieves y el de la Bella Durmiente, si bien se registran lienzos puntuales dedicados a otros relatos de la Literatura Infantil y Juvenil, según

Tanto es así que en 1857 William Holman Hunt, Dante Gabriel Rossetti y el ya mencionado Millais (los fundadores de la Hermandad Prerrafaelita) ilustraron una nueva edición de los poemas de Tennyson. 
tendremos ocasión de exponer a lo largo de las siguientes páginas. No obstante, no hay que perder de vista el hecho de que estos cuentos o ciclos elegidos no fueron concebidos como obras de la Literatura Infantil ni estaban dedicadas a los niños, sino que su origen se remonta a la literatura popular, razón por la que las versiones más antiguas contienen no pocos elementos escabrosos, y su misión original era adoctrinar al pueblo iletrado sobre las consecuencias de sus malas acciones y el peligro que estas conllevaban.

La presente propuesta tiene como metodología la descripción, análisis e interpretación de los cuadros que integran cada uno de estos ciclos y su objetivo consiste en reflexionar sobre cómo la iconografía constituye un recurso didáctico de naturaleza visual -con potente capacidad mnemotécnica- para abordar las distintas versiones de los cuentos de hadas en el aula, especialmente en la asignatura de "Didáctica de la Literatura y la Literatura Infantil" de los Grados de Educación Infantil y de Educación Primaria. Todo ello en un hermoso ejemplo de la relación intertextual entre Literatura y Pintura.

\section{La Cenicienta}

Los pintores prerrafaelitas se inclinaron normalmente por el relato de Charles Perrault (1697) a la hora de recrear pictóricamente al personaje de Cenicienta ${ }^{3}$. Los lienzos dedicados a esta huérfana que acabaría convirtiéndose en princesa son, fundamentalmente, los tres que se abordan en las siguientes líneas.

En primer lugar, Edward Burne-Jones (Wood, 1999) retrata en 1863 a una Cenicienta vestida con harapos en su medio natural, es decir, las cocinas de la casa de su padre, como se desprende de la vajilla y demás recipientes dispuestos sobre el aparador que sirve de fondo.

Burne-Jones capta a la protagonista de su cuadro después de que esta haya regresado del segundo baile en palacio, pues, de hecho, ya ha perdido uno de sus zapatos. La circunstancia de que la zapatilla que aún calza sea de cristal -a juzgar por su transparencia- y no de oro es el dato que permite confirmar que la versión elegida por el artista es la de Perrault y no la de los Hermanos Grimm, en cuyo cuento la heroína asiste al palacio con zapatos aúreos.

Llama la atención la presencia de una rosa, situada inesperadamente entre la loza, a la derecha de la joven y a la altura de su rostro. Con esta flor, uno de los atributos iconográficos por excelencia de Afrodita (Grimal, 1981, 12b) ${ }^{4}$, el pintor vincula a su Cenicienta con la diosa griega, haciéndola portadora de una belleza sublime (en efecto, el rostro dibujado por Burne-Jones no está oculto bajo la ceniza ni el hollín consustanciales al personaje), capaz de enamorar perdidamente al príncipe del reino.

\footnotetext{
El arquetipo que encarna esta joven ha recibido diversos nombres en las distintas versiones que ha protagonizado desde el antiguo Egipto; en nuestro caso, optamos por el nombre de "Cenicienta" dado que en el momento en que se ejecutan los lienzos prerrafaelitas la condición de la joven cubierta de cenizas era la que se había impuesto ya en lo relativo a su identificación.

4 El ruso Yevgueni Shvarts escribió en 1938 una obra de teatro titulada Zolushka, cuyos motivos principales son las palomas, los zapatos y las diferentes variantes del árbol. Las palomas son otro de los atributos iconográficos de Afrodita, pues eran su animal favorito y, de hecho, arrastraban su carro. En cualquier caso, el tema de las palomas nos retrotrae de nuevo a la fuente textual, dado que dichas aves constituyen un elemento esencial en la versión de los Grimm.
} 


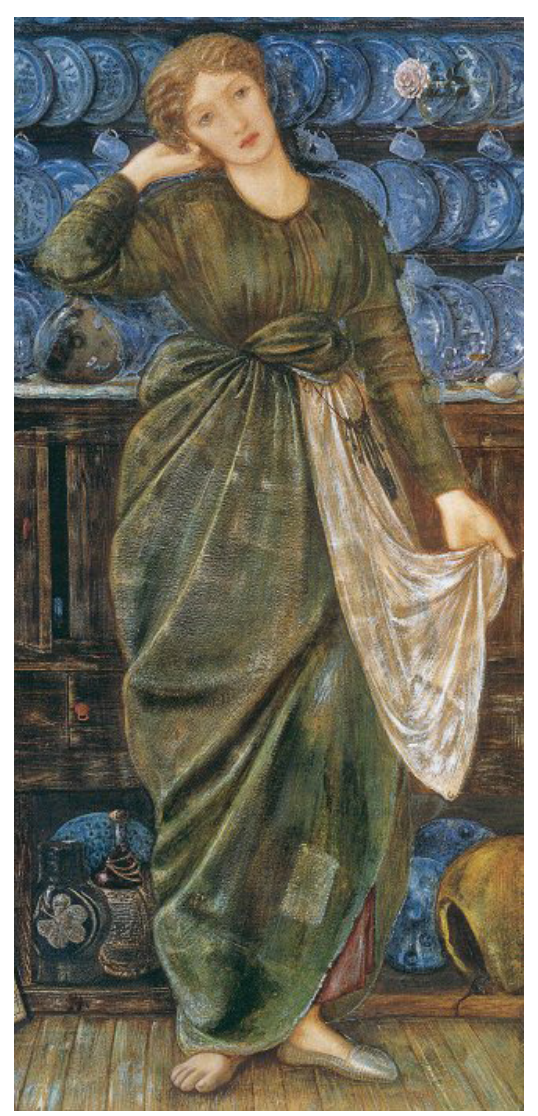

Figura 1: Cinderella, de Burne-Jones

Por su parte, lo más llamativo de la tela firmada por John Everett Millais (Barlow, 2005; Rosenfeld, 2012) en 1881 es el hecho de que plasma a una Cenicienta todavía adolescente, casi una niña. Sentada en un humilde taburete, descalza, sumida en un fuerte claroscuro y mirando fijamente a la izquierda del espectador (en la dirección de donde procede la luz), la Cenicienta de Millais se encuentra rodeada de material para encender la lumbre, tarea de la que procede su universal apodo, en un momento impreciso e intemporal del relato. El lienzo no incluye elementos que permitan concluir si se sigue la versión francesa o la alemana, o, acaso, fuentes anteriores del relato (Bettelheim, 2006, 277-325).

Muy intrigante resulta la pluma de pavo real que la joven sostiene en su mano derecha. Desde una perspectiva hermenéutica, se trata de un atributo muy elocuente: $y$ es que a eso ha quedado reducida la muchacha, que, como un pavo real desplumado, ha sido despojada de todos sus bienes y su hermosura por obra y gracia de sus crueles madrastra y hermanastras. No obstante, y de acuerdo con la cultura romana -en la que princesas y emperatrices tomaron el pavo real como su símbolo personal (Cirlot, 1992, 356)-, esta pluma vaticina y anuncia simultáneamente al espectador el futuro de Cenicienta convertida en princesa. 
Finalmente, Val Prinsep (Prettejohn, 2000), como se le conoce habitualmente, presenta en 1899 una Cenicienta joven, vestida de manera muy humilde y rodeada de escobas y fogones.

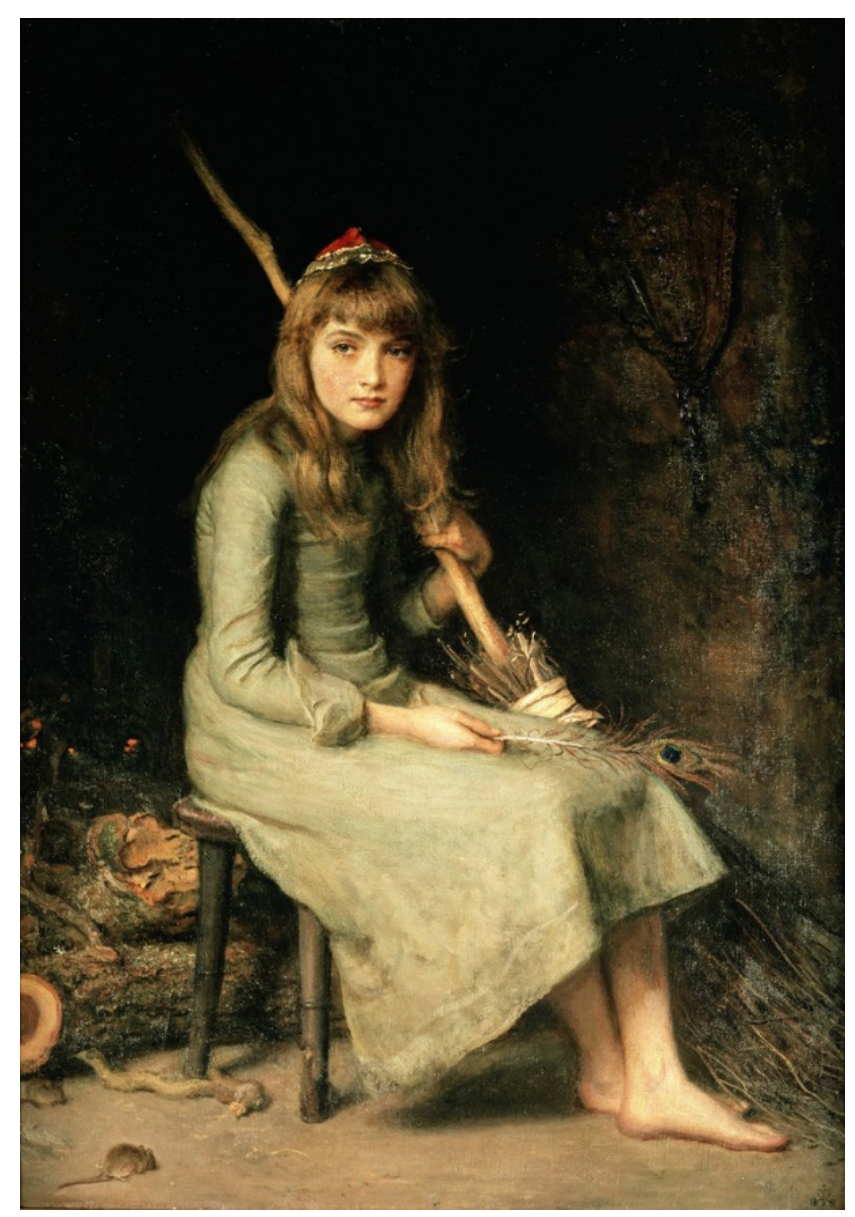

Figura 2: Cinderella, de Millais

La presencia de una ristra de ajos en el ángulo superior izquierdo y de una calabaza en el inferior izquierdo confiere un aire costumbrista al lienzo, y lo acerca al género del bodegón. Pero al margen de estas consideraciones propias de la metodología de la Historia del Arte, la inclusión de una calabaza proporciona información acerca de la fuente literaria utilizada y del momento recreado del relato.

Así pues, Prinsep pinta de nuevo a la Cenicienta de Perrault, y lo hace cuando esta ha regresado del primer o segundo baile en palacio (al ir descalza, no se puede inferir si ya ha perdido uno de sus zapatos o no). Roto el hechizo del hada madrina, la carroza ha vuelto a ser una vulgar hortaliza y la bella dama luce -o desluce- de nuevo como esforzada criada. Pero algo se ha transformado en ella, como sugiere su rostro vuelto hacia la luz, con una mirada soñadora y media sonrisa dibujada en sus labios, como si estuviera evocando la velada o veladas previas bailando en el palacio con su príncipe. 
A pesar de que esta obra no incluye elementos causantes de extrañamiento como las dos analizadas en líneas anteriores (la rosa y la pluma de pavo real, respectivamente), tanto la calabaza como la lumbre desempeñan un importante papel iconográfico, de modo que si el lienzo careciese de título podría identificarse sin lugar a dudas con la heroína de este cuento de hadas.

\section{Blancanieves}

Los dos lienzos más importantes que recrean este relato difundido por los Hermanos Grimm (1812) pero cuyos orígenes se remontan a una larga tradición (Bettelheim, 2006, 235-252) privilegian el momento del primer encuentro entre Blancanieves y los enanitos, mientras que obvian al personaje de la madrastra y su espejo mágico.

Durante la década de 1890 Batten se consagró a la ilustración de distintas colecciones de cuentos de hadas. En este contexto, en 1897 dedicó una témpera sobre lienzo a Blancanieves (Snow White and the Seven Dwarves) que recrea el momento en el que los enanitos descubren a la doncella durmiendo sobre una de sus pequeñas camas. Llama la atención cómo la caracterización física de la doncella se aparta de la propuesta por los Hermanos Grimm en su célebre relato en tanto en cuanto la Blancanieves de Batten no tiene el pelo negro como el ébano. Asimismo, los enanitos no están representados como pequeños hombrecillos, sino que más bien aparecen como si de elfos de la mitología nórdica (Bernárdez, 2002, 141) se tratara -con cierto aire lascivo, además-, y por tanto muy alejados de la imagen entrañable y bonachona universalizada por Walt Disney algunas décadas después.

En otro orden de cosas, Henry Meynell Rheam (Werner, 2005) había llevado a cabo una primera incursión en el tema de Blancanieves en el lienzo homónimo (1902), en el que la joven aparece acompañada por cinco enanitos en la espesura del bosque ${ }^{5}$. Curiosamente, estos diminutos seres también aparecen caracterizados como gnomos de la mitología escandinava, al igual que sucedía en la témpera de Batten.

Un lustro después, este autor abordará el cuento de Blancanieves propiamente dicho, y lo hará bajo el elocuente título de Érase una vez ... (1908). En él se aleja del relato ortodoxo al propiciar el encuentro entre los enanitos y la princesa en la espesura del bosque, en plena huida del cazador y de los perversos planes de su madrastra. Los enanitos representados por Rheam son más amables que los de su compatriota Batten, pero su doncella se aparta también de la prosopografía clásica: sus cabellos no son negros, sino cobrizos, siendo la cabellera ígnea de las figuras femeninas que representan una de las señas de identidad de los pintores prerrafaelitas (Bornay, 1994, 103-108; Dunn, 2000, 55-64).

En The Fairy Wood, firmado en 1903, un pequeño cortejo de pajecillos, ataviados cual duendes, ayudan a una dama -que bien podría ser una princesa, o la propia Blancanieves- a llevar la cola de su hermoso vestido por la alfombra de lavandas que tapiza el bosque, mientras que al fondo se ve pasar a un caballero armado en su montura. 


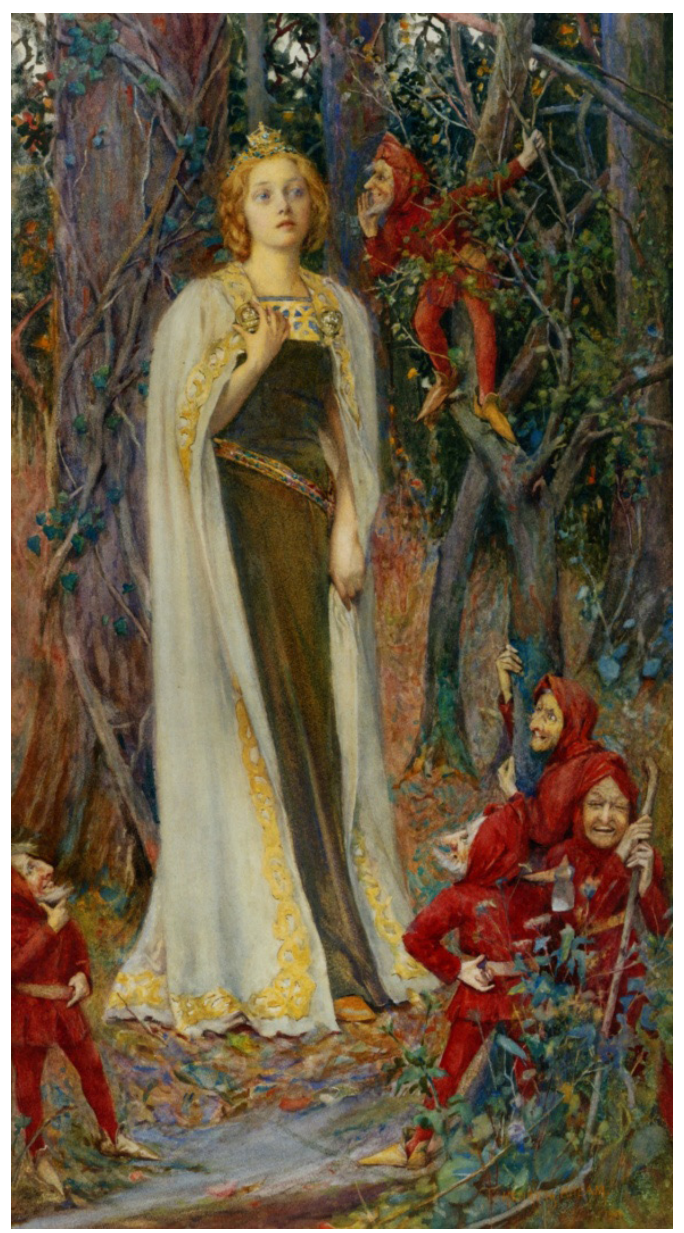

Figura 3: Primera versión de Blancanieves de Meynell Rheam

\section{La Bella Durmiente}

Sin lugar a dudas, es al cuento de La bella durmiente al que mayor atención ha dedicado la Historia del Arte y, en particular, la pintura prerrafaelita, cuyos integrantes se inclinaron por distintas versiones de un relato rico en fuentes (Bettelheim, 2006, 264-276).

Entre 1885 y 1890 Edward Burne-Jones (MacCarthy, 2011) realiza The Legend of Briar Rose, una serie de cuatro lienzos de grandes dimensiones en los que plasma la parte final del relato según los Hermanos Grimm. El primer panel, titulado "El bosque de zarzarrosas", recoge el momento en el que el príncipe atraviesa la vegetación que precinta el castillo, y allí descubre dormidos a los soldados, cuyos cuerpos han sido entrelazados por las ramas de las gavanzas ${ }^{6}$. En este extremo, sin embargo, la escena representada se acerca más al pasaje de Perrault, que es el que hace alusión

6 Flores del gavanzo, un arbusto silvestre muy parecido al rosal que recibe el nombre de zarzarrosa o escaramujo. La gavanza se conoce también como rosa canina. 
específica a los "guardias" entre los cortesanos hechizados. "La cámara del Consejo" muestra a los miembros del Consejo real también traspuestos, al igual que el rey, desplomado sobre su trono. Bajo la cortina del fondo se descubren más soldados dormidos. En el tercer panel, "El jardín de la corte", se observa a las tejedoras dormidas sobre sus telares. Las paredes del castillo y los arcos de rosas forman el telón de fondo de la pintura. Por último, "El cenador de rosas" presenta a la protagonista en su lecho, rodeada de sus doncellas dormidas, mientras la zarzarrosa cubre todo el cortinaje del fondo.

El hecho de que el soberano aparezca dormido en una de las telas de la serie confirma que la versión plasmada por Burne-Jones es la alemana, dado que en la de Charles Perrault los reyes abandonan el castillo antes de que la corte quede sumida en el sueño.

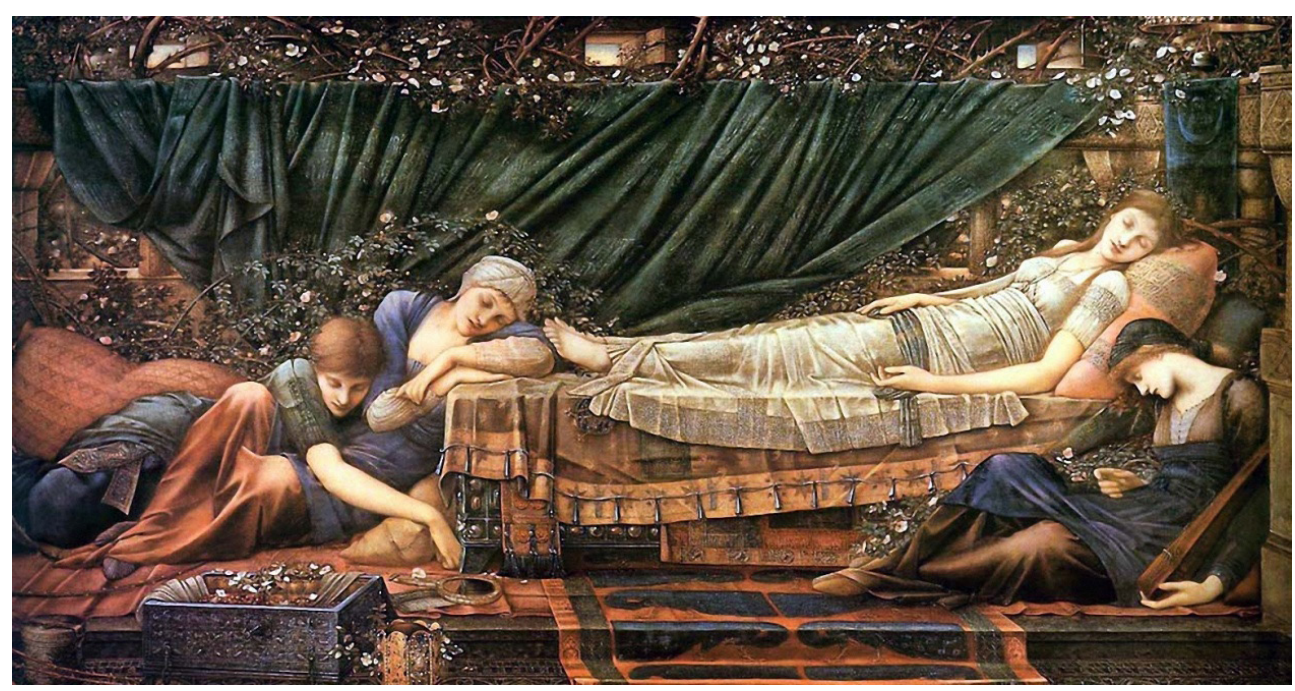

Figura 4: Representación de la princesa según Burne-Jones

Al margen de esta "tetralogía”, el pintor británico había diseñado a partir de 1862 una serie de azulejos con nueve escenas de La bella durmiente ${ }^{7}$ que guardan una notable similitud compositiva con los lienzos (Huxtable, 2009, 38-41). En el fondo, unos y otros habrían de servir de ensayo -sobre todo en lo referido, precisamente, a la composición- para El sueño del rey Arturo en Avalon (1881-1898), su último cuadro y una de sus obras maestras, con una temática concomitante a la de este cuento de hadas (Tennyson, 2002, 64-83) ${ }^{8}$.

Dos años antes de representar a Blancanieves e inmerso como estaba en la ilustración de cuentos de hadas, John Dickson Batten dedicó otra témpera a la Bella Durmiente $^{9}$. El artista no escoge, sin embargo, el momento del relato representado

Tales escenas abarcan desde el nacimiento de la protagonista hasta el enlace de los príncipes.

8 Arturo, mortalmente herido tras la última batalla contra Mordred, es llevado por tres hadas hasta la isla mágica de Avalon, donde permanecerá en un ensueño hasta que su presencia sea requerida de nuevo en la tierra.

$9 \quad$ Y aún habría de realizar otra más sobre La bella y la bestia en 1904. 
por sus colegas - la princesa dormida en su cama a punto de ser despertada por el caballero-, sino que se inclina por otro menos habitual: el de la doncella a punto de pincharse con el huso de la rueca (de ahí su título original, Sleeping Beauty: The Princess Pricks Her Finger, c. 1895). De nuevo es el análisis iconográfico el que arroja datos sobre la escena recreada: así, en la pintura en cuestión la presencia de una anciana malencarada y totalmente vestida de negro -como si de una bruja o una hechicera malvada se tratara- reafirma que el relato plasmado por Batten es el de los Hermanos Grimm, el único en el que la actitud de la hilandera con la que se encuentra la protagonista resulta ambigua ${ }^{10}$. En este sentido, la presencia de un gato negro, en principio ajeno al relato, refuerza esta connotación diabólica y, por tanto, que la fuente literaria sea el relato alemán.

Por su parte, Edward Frederick Brewtnall ejecuta un cuadro de prerrafaelismo tardío que recoge el momento en el que el príncipe encuentra a la doncella dormida, sin más claves iconográficas que permitan deducir cuál de las tres versiones es la plasmada. Podría tratarse incluso de la italiana, la de Giambattista Basile, en la que Talía - que así se llama la princesa en esta versión- yace dormida tras haberse clavado una astilla de lino bajo la uña. Un rey llega por casualidad hasta ella y, embelesado por su belleza y creyendo que está muerta, la viola y la deja encinta.

Casi una década antes de firmar sus Blancanieves, a las que ya nos hemos referido más arriba, Rheam había abordado el cuento de La bella durmiente (1899). Se trata de una versión amable y elegante, dado el protagonismo que se concede a las telas y a las flores de la zarza, que ha penetrado incluso por la ventana. Sin embargo, y al igual que sucede con el lienzo de Brewtnall, no hay pistas que permitan identificar la escena con una fuente literaria concreta.

Probablemente la de John Collier (Wood, 1983) sea la última representación de La bella durmiente aportada por el movimiento prerrafaelita, pues data de $1921^{11}$. Una vez más se retrata a la protagonista del cuento dormida, víctima del hechizo al que ha sido sometida. La presencia de dos doncellas junto a su lecho elimina la posibilidad de que el relato plasmado sea el de Basile, aunque no se descubre ningún otro elemento que incline la balanza hacia Perrault o los Grimm. Es la de Collier una visión regia y opulenta de la escena, a juzgar por los ropajes aterciopelados y brocados de las tres figuras femeninas, la cortina-dosel adamascada, la madera labrada de la cama y del zócalo, las vidrieras que cubren las ventanas, etcétera. Sobresale la fuerte impronta medievalizante del lienzo, de forma que el autor acerca a la princesa a otras damas por él representadas, como Lady Godiva (1897) o La Reina Ginebra (1900).

\section{Otros textos de Literatura Infantil en la pintura prerrafaelita}

Al margen de estos tres grandes ciclos pictóricos que constituyen Cenicienta, Blancanieves y, sobre todo, la Bella Durmiente, la corriente prerrafaelita se interesó por otros textos de LIJ, si bien de forma más puntual y aislada, como sucede en los ejemplos que siguen.

Los textos de Basile y de Perrault insisten en que la hilandera es inocente.

11 También en el primer tercio del siglo XX se data la pintura La princesa durmiente (1900-1926), de Víktor Vasnetsov, pero, evidentemente, del todo ajena al prerrafaelismo. El ruso Vasnetsov se especializó en temas mitológicos e históricos, pero también se dedicó a ilustrar cuentos de hadas eslavos. 


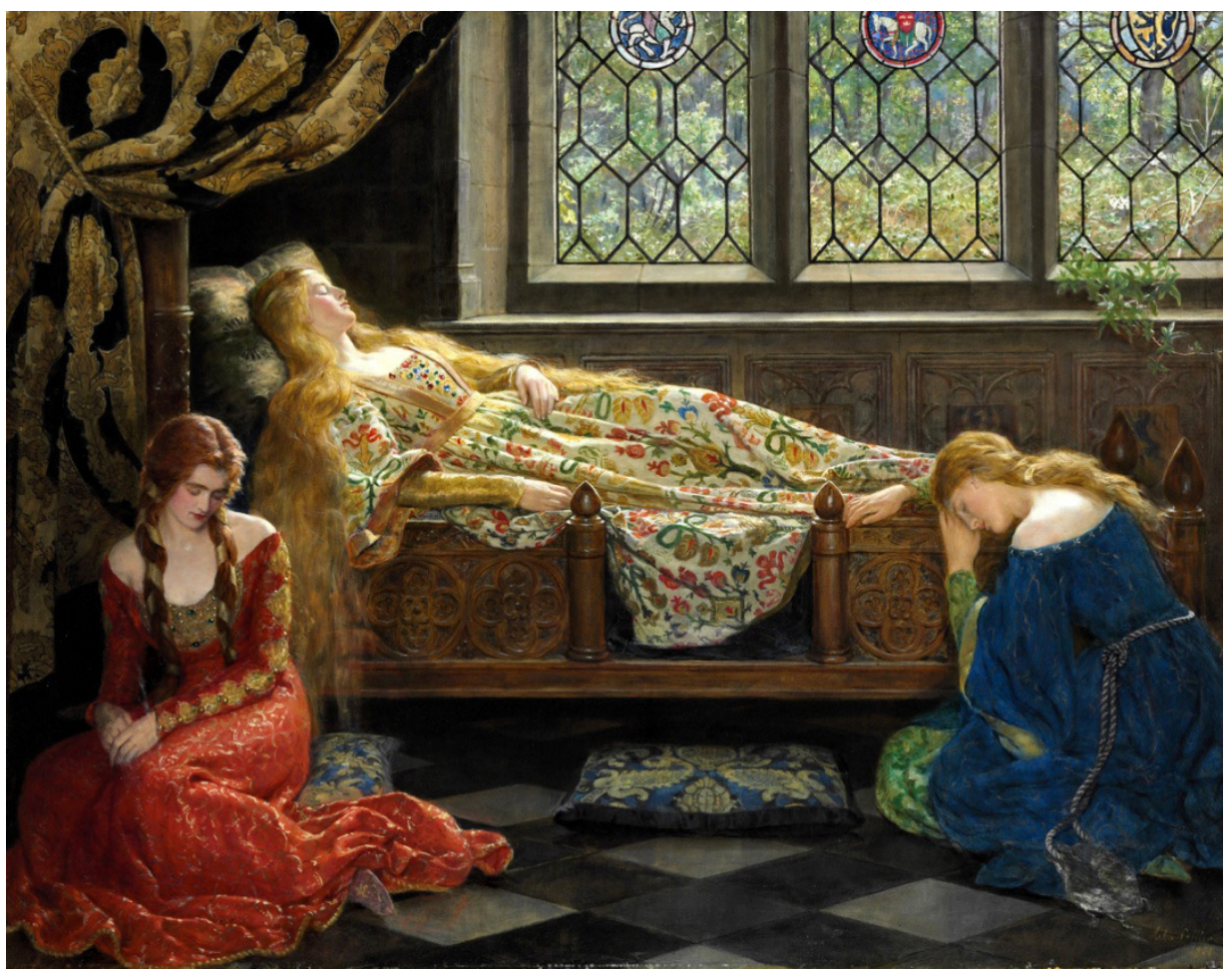

Figura 5: La elegante escena recreada por Collier

En 1862, a su regreso de un viaje por Venecia y Milán, Burne-Jones comenzó el cuadro titulado Fátima, en el que representa a la última mujer de Barba Azul ${ }^{12}$. Para ello fusionó dos fuentes literarias: los Cuentos de Mamá Oca (1697, según se ha señalado anteriormente en referencia a El zapatito de cristal), de Charles Perrault, y la ópera Barba Azul, o la curiosidad femenina (1798), que ambienta la historia en Turquía y da a la joven el nombre de Fátima ${ }^{13}$. Véronique Gerard-Powell ha llevado a cabo un análisis del lienzo que merece la pena reproducir:

Burne-Jones no escoge el momento dramático y habitual del descubrimiento de los cadáveres, sino un instante que centra la atención del espectador en el gesto fatal de Fátima. Transmite íntegramente el espíritu del texto: el color oscuro y la puertecita del fondo recuerdan su descenso precipitado por la escalera secreta. El manojo de llaves que su marido le ha confiado cuelga de su cintura. "Al llegar a la puerta del gabinete se detuvo algún tiempo pensando en la prohibición que le había hecho su marido, y en que podría sucederle alguna desgracia por ser desobediente". Pero, al ser su curiosidad demasiado fuerte, "cogió la llavecita y abrió,

12 Tal vez comentara la elección de este tema con el crítico John Ruskin, que le había acompañado en este viaje a Italia y era, a su vez, autor de cuentos y especialista en los Hermanos Grimm, de los que prologaría en 1868 una edición inglesa.

13 Dado que ya se encontraba diseñando azulejos sobre el tema de La bella durmiente (conservados en el Victoria and Albert Museum) para William Morris -el fundador del movimiento Arts and Crafts-, el pintor conocía muy bien los cuentos de Perrault. 
temblando, la puerta del gabinete": su mano derecha está girando la llave en la cerradura, al tiempo que su mirada fija subraya que no logra dominar su curiosidad $(2014,72)$.

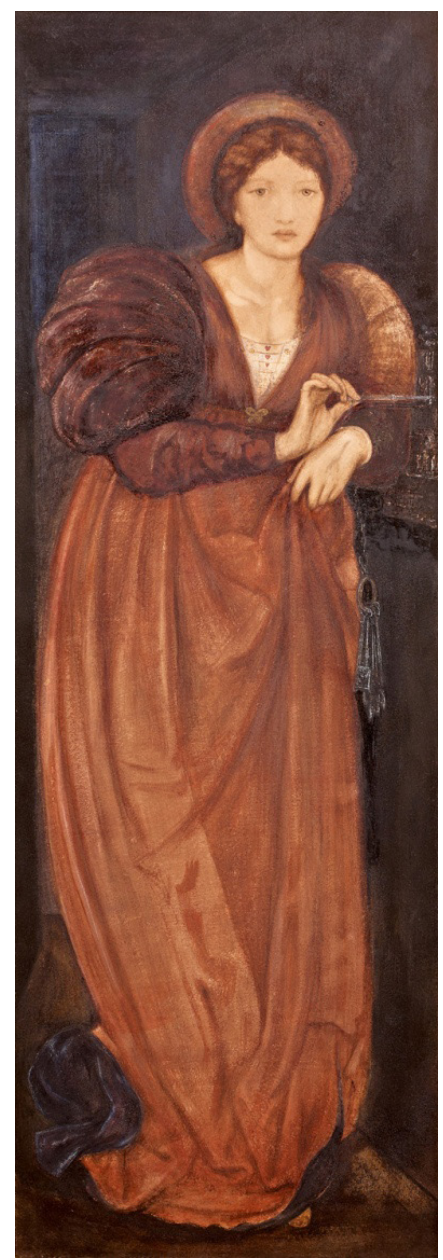

Figura 6: La relectura en pinceladas de Barba Azul por parte de Burne-Jones

Así pues, con la representación de la protagonista de Barba Azul, Burne-Jones introduce el mito de la mujer fatal, uno de los leitmotivs de la pintura prerrafaelita (Bornay, 1990), en los cuentos de hadas.

Por otro lado, en la primera etapa de su carrera, Henry Arthur Payne demostró un vivo interés por el mundo de las brujas y de las magas (Christian, 1993). Así lo demuestran, entre otros, La bruja (1898) y El mar encantado, fechado en torno al año siguiente. Payne encuentra su fuente de inspiración en un relato fantástico, dividido en varios cuentos, titulado The Shaving of Shagpat, escrito por George Meredith en 1856 en el estilo de Las mil y una noches.

En concreto, el lienzo representa la aventura narrada en Goorelka de Oolto, la cual lleva a Shibli, un barbero persa, y a su halcón parlante, al palacio del rey de 
Oolto, cuya hija, la maga Noorna, es la guardiana del lirio del mar encantado. Para llegar hasta éste, la hechicera utiliza una concha de berberecho que guarda bajo su almohada. Con el fin de hacerse con ella, Shibli consigue entrar en los aposentos de la princesa, la cual, al percatarse de esta presencia masculina, huye en esa misma concha por el mar.

Payne concibe su cuadro como una ilustración del texto de Meredith: la presencia del halcón, que delata la presencia de Shibli en la parte inferior de la concha; la actitud pensativa e inquieta de Noorna en su tentativa de fuga; los mástiles y las velas de los barcos encantados, y, sobre todo, los rostros femeninos flotantes, que responden al pasaje: "(...) Figuras de mujeres de piel clara iban tendidas a lo largo siguiendo la corriente y levantaban la cabeza conforme pasaban raudas al compás de las olas." (Meredith, 2003, 120).

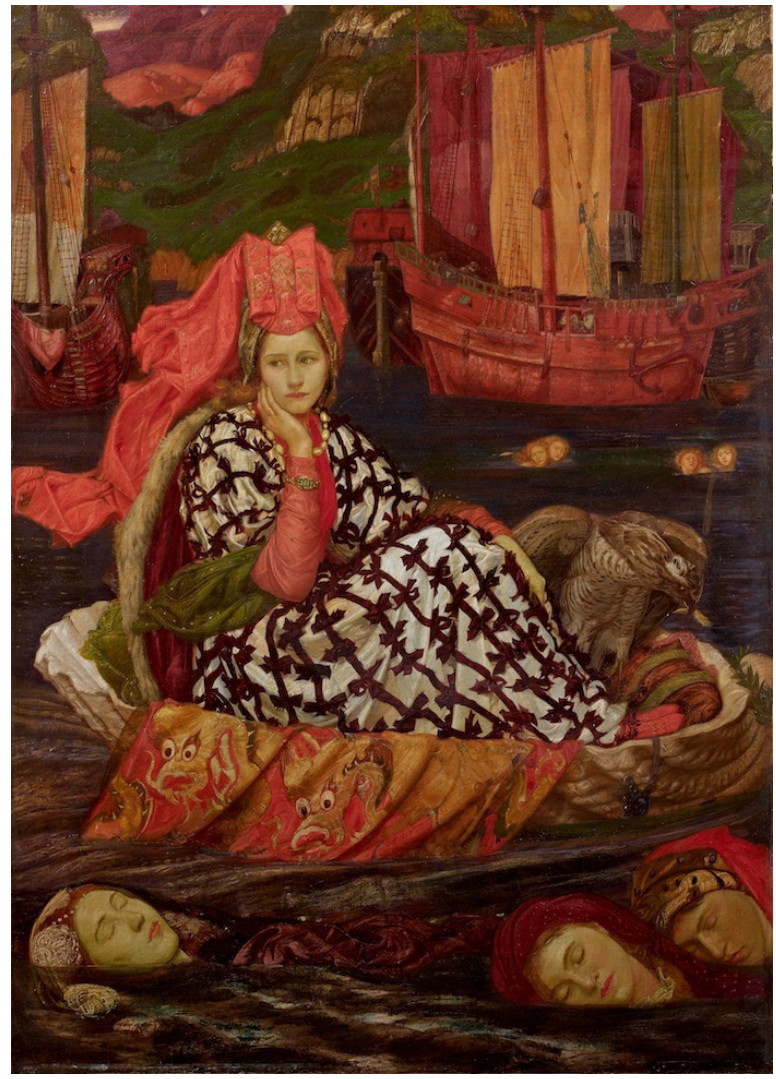

Figura 7: El protagonismo femenino en la tela de Payne

Y es que la figura de la hechicera, por su obvia vinculación con la femme fatale, también ejerció fascinación sobre los prerrafaelitas, como bien demuestra la tríada dedicada por Waterhouse a la bruja Circe ${ }^{14}$, además de los lienzos titulados Destino (1900), La bola de cristal (1902) y Medea (1907), o por Frederick Sandys al hada Morgana (1864) y a la extranjera enamorada de Jasón (1868).

14 Circe offering the cup to Ulisses (1891), Circe Invidiosa (1892) y The Sorceress (c. 1911). 


\section{Conclusión, o de cómo las distintas versiones de los cuentos confluyen en la lectura feminista finisecular}

Desde la experiencia del aula, resulta poderosamente llamativo comprobar cómo los alumnos de tercer curso de los Grados de Educación Infantil y Primaria creen fervientemente que la única e indiscutible versión de los cuentos de hadas en la acuñada por la factoría Disney en sus películas de animación. La gran mayoría desconoce no solo el proceso de evolución de estos relatos sino sobre todo las distintas versiones que existen de los mismos, por lo que asisten atónitos al descubrimiento de los abundantes elementos escabrosos (al menos para un receptor infantil, como pueden ser las amputaciones a las que se hace referencia en la Cenicienta de los Hermanos Grimm o la ya mencionada violación que tiene lugar en Talía, Sol y Luna, de Giambattista Basile) que muchos de estos suelen incluir, tan alejados de las edulcoradas versiones de las "princesas Disney".

Es precisamente en el actual contexto revisionista que desde el discurso femenino se está desarrollando en torno al personaje de la "princesa de cuento" (piénsese, por poner un solo ejemplo entre los miles posibles, en el cuento que la editorial argentina Chirimbote acaba de dedicar a Frida Kahlo, dentro de la colección "Otras princesas") y a la clásica noción de "amor verdadero" (paradójicamente, la propia Disney ha aportado dos modelos recientes de gran trascendencia, primero en Frozen -2013 - y unos meses más tarde en Maléfica -2014-) donde adquiere plena vigencia la pintura de LIJ por parte de la Hermandad Prerrafaelita, más allá incluso de la discriminación de las distintas versiones de los relatos populares en función de la iconografía que hemos expuesto previamente.

Los cuentos de hadas suscitaron tanto interés en los pintores prerrafaelitas porque cumplen dos requisitos básicos para ellos: un cronotopo fácilmente asimilable a lo medieval y, sobre todo, el papel preponderante de la figura femenina. El primer aspecto permite a estos artistas integrar con toda naturalidad los cuentos en los relatos de índole legendaria que representan casi de continuo, ya procedan de la Mitología Clásica, del ciclo artúrico o de las tramas de Shakespeare (Danesi, 1997, 69-94). Asimismo, que la mujer sea el centro de atención en la mayoría de los cuentos de hadas coincide con la renovación de la perspectiva de lo femenino que establece el movimiento prerrafaelita en plena sociedad victoriana (Azam, 2014, 71-78).

Por ello, entre todos los lienzos analizados en páginas previas, cobra especial importancia la Fátima de Burne-Jones, pues es el que rompe con la imagen tópica de la mujer cándida y dócil que suele encarnar la princesa de los cuentos de hadas y por la que se apuesta en el remilgado contexto finisecular británico (De Girolami, 2004, 197-227; Holland, 2013, 75-98). La esposa de Barba Azul osa desobedecer a su marido -y no por simple curiosidad- y descubre así estar casada con un asesino, cuyo final precipita (Nead, 1988). Parece que ya no todos fueron felices y comieron perdices, y empiezan a tambalearse los pilares del férreo orden establecido (Harrison y Taylor, 1992; Miquel-Baldellou, 2008, 179-190).

Algunas décadas más tarde, pero coincidiendo con el máximo apogeo de la obra de un prerrafaelita de la talla de Waterhouse (Hobson, 1989), el suizo Robert Walser 
publicaba en 1902 la pieza de teatro Blancanieves ${ }^{15}$ (Walser, 2015), en la que plantea una imprevista segunda parte del cuento, de forma que el relato se inicia in medias res, en el punto en que quedaba concluido el cuento de los Hermanos Grimm ${ }^{16}$ (Walser, 1997). A fin de cuentas, el texto de Walser incide en los ingredientes psicoanalíticos en los que reside la universalidad de Blancanieves: esa amalgama de pasiones femeninas en la que concurren la competitividad y la envidia por poseer la belleza y la juventud, es decir, la condición de ser deseable y deseada por los hombres (Iannou, 2014, 1-14), y que se remonta al mito clásico que vincula a Afrodita, la diosa del amor y la belleza, con Psique, la joven mortal de inconmensurable hermosura destinada a ser la esposa de su hijo (Grimal, 1981, 458b-459b). Por ello, la presencia de la manzana en Blancanieves adquiere una importancia simbólica de gran trascendencia: es el icono que convierte a la malvada madrastra en una prolongación de la Eva bíblica - la portadora del fruto prohibido- y de la Venus pagana -receptora de la manzana de oro que desata la Guerra de Troya-y, por tanto, en una de las encarnaciones más tempranas del mito de la "mujer fatal" o femme fatale (Bornay, 1990) que tanta fortuna habría de cosechar en el imaginario del siglo XIX, época en la que los Grimm dieron forma a su relato (García-Manso, 2017).

Desde esta perspectiva pueda entenderse tal vez por qué los prerrafaelitas no representaron en ningún caso "La Sirenita" (1837), de Hans Christian Andersen, dada, paradójicamente, la atracción que esta criatura ejercía sobre ellos: y es que en su nuevo concepto del rol femenino (Stott, 1992) no tiene cabida la mujer sacrificada por amor que describe el cuento danés, sino la bella y perversa mujer-pez que arrastra al hombre a las profundidades del mar ${ }^{17}$. Los cuentos de hadas, pues, son objeto en la cultura del Ochocientos y en la pintura prerrafaelita (Dijkstra, 1986) de otra vuelta de tuerca que enlaza oportunamente con las actuales reflexiones sobre los mensajes implícitos de la LIJ y el papel desempeñado por la Didáctica en su adaptación al mundo presente. Un repertorio como el ofrecido en las presentes páginas permite un examen comparado tanto de las fuentes de los relatos como de sus claves hermenéuticas en la pintura con la finalidad última de que sea útil para el uso docente.

15 Aparte de Blancanieves, compuso otros tres dramolettes: Cinderella, Thorn Rose, the Sleeping Beauty (todos ellos en verso) y Rapunzel (este último en prosa).

16 La trama que desarrolla Walser en su opúsculo es, a grandes rasgos, la siguiente: Blancanieves reprocha a su madrastra sus intentos de homicidio con respecto a ella y no acepta las disculpas de la reina. Asimismo, echa en cara al cazador que se dejara convencer, mediante las artimañas de seducción de la madrastra, para perpetrar su asesinato. Más tarde, el príncipe confiesa a Blancanieves que en realidad es a la reina a quien ama, y se arrepiente de no haber dejado a la primera sumida en su sueño de muerte dentro del cajón de cristal. Contra todo pronóstico, la protagonista pide disculpas a la madrastra por las acusaciones que ha vertido sobre ella, al tiempo que la reina admite que fue la envidia que sentía hacia su belleza lo que la empujó a planear este crimen. Tiene lugar la confesión de amor de la reina al príncipe, quien se entrega a ella. Blancanieves ordena al cazador que lleve a cabo una representación de cómo habría cometido su asesinato. Expresa a continuación su deseo de regresar al bosque con los enanitos y vuelve a reprochar a su madrastra el indigno comportamiento que ha demostrado. El cazador interviene para señalar que el cuento mintió, puesto que la Reina realmente no envidiaba la belleza de Blancanieves. Esta lo acepta y añade que la manzana tampoco estaba envenenada. Tras el beso filial entre ambas mujeres, en los últimos minutos de la cinta interviene el rey, el padre de Blancanieves, personaje que realmente no había fallecido.

17 La que aparece representada, por ejemplo, en The Depths of the Sea (1887), de Edward Burne-Jones, o The Siren (1900), de John William Waterhouse. 


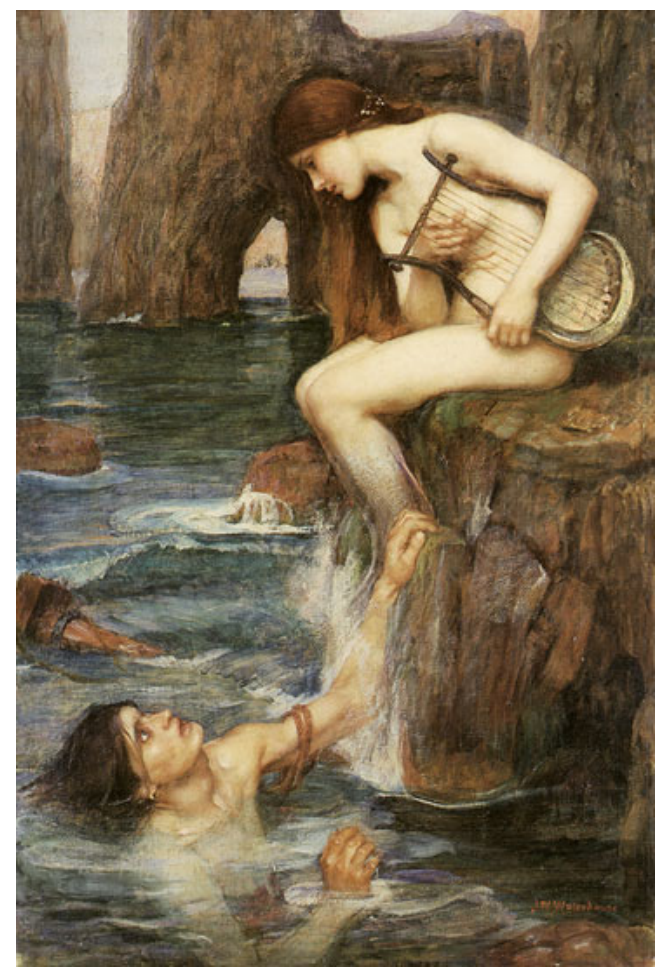

Figura 8: La mujer-pez y su víctima

\section{Bibliografía}

Azam, Azmi (2014): "Victorian Ethics in Pre-Raphaelite Art: Depiction of the Fatale Fall of Femme", IOSR. Journal of Humanities and Social Sciences, 19, 71-78.

Barlow, Paul (2005): Time Present and Time Past: The Art of John Everett Millais, Farnham, Ashgate.

Basile, Giambattista (2006): El Pentameron: El cuento de los Cuentos, Madrid, Siruela.

Bernárdez, Enrique (2002): Los mitos germánicos, Madrid, Alianza Editorial.

Bettelheim, Bruno (2006): Psicoanálisis de los cuentos de hadas, Barcelona, Crítica.

Bornay, Erika (1990): Las hijas de Lilith, Madrid, Cátedra.

Bornay, Erika (1994): La cabellera femenina, Madrid, Cátedra.

Christian, John (Ed.) (1993): The Last Romantics: The Romantic Tradition in British Art. Burne-Jones to Stanley Spencer, London, Lund Humphries Publishers.

Cirlot, Juan Eduardo (1992): Diccionario de símbolos, Barcelona, Labor.

Danesi, Silvia (1997): “La Edad Media revisitada: The Pre-Raphaelite Brotherhood”, en El pasado en el presente: El revival en las artes plásticas, la arquitectura, el cine y el teatro, Argan, Giulio Carlo (et al.), Barcelona, Gustavo Gili, 69-94.

De Girolami Cheney, Liana (2004): "Edward Burne-Jones' Andromeda: Transformation of Historical and Mythological Sources", Artibus et Historiae: An Art Anthology, 49, $197-$ 227. 
Dedebas, Eda (2011): “Christina Rossetti’s Speaking Likenesses: Different Form of Travel in Victorian Children's Literature", Extravio: Revista Electrónica de Literatura Compara$d a, 6,53-68$.

Dijkstra, Bram (1986): Idols of Perversity: Fantasies of Feminine Evil in Fin-de-Siecle Culture. New York and Oxford, Oxford University Press.

Dunn, Vicki (2000): "Hair and Sexuality as Represented in Selected Works of Rossetti, the Preraphaelites and Elizabeth Barret Browning Pre-Raphaelites", en Mujer e identidad, distintas voces: ensayos sobre literatura y traducción, Ramírez Jaimez, Ana Sofía (Coord.), Las Palmas de Gran Canaria, Chandlon Inn Press, 55-64.

Fink, Nadia (2016): Frida Kahlo para niñas y niños, Zaragoza, Chirimbote/Maime Mujer España.

García-Manso, Angélica (2017): "Versiones transgresoras y polémicas de Blancanieves: de Robert Walser a João César Monteiro", Signa: Revista de la Asociación Española de Semiótica, 26 [en prensa].

Gerard-Powell, Véronique (2014): "La pintura victoriana en la Colección Pérez-Simón”, en Alma-Tadema y la pintura victoriana en la colección Pérez-Simón, Vv.aa., Madrid, Fundación Colección Thyssen-Bornemisza, 19-23.

Grimal, Pierre (1981): Diccionario de mitología griega y romana, Barcelona, Paidós.

Grimm, Jacob y Wilhelm (1868): German Popular Stories, London, John Camden Hotten.

Grimm, Jacob y Wilhelm (2015): Cuentos completos I, Madrid, Alianza Editorial.

Harrison, Antony H. y Taylor, Beverly (Eds.) (1992): Gender and Discourse in Victorian Literature and Art. DeKalb, Northern Illinois University.

Hobson, Anthony (1989): J. W. Waterhouse, London, Phaidon.

Holland, Kathryn (2013): "Late Victorian and Modern Feminist Intertexts: The Strachey Women in A Room of One's Own and Three Guineas", Tulsa Studies in Women's Literature, 32 (I), 75-98.

Iannou, Maria (2014): "Beauty, Feminism, Art. Constructing female identity through the discourse of beauty", en Female Beauty in Art: History, Feminism, Women Artist, Iannou, Maria y Kyriakidou, Maria (Eds.), Newcastle upon Tyne, Cambridge Scholars Publishing, 1-13.

Keats, John (1997): Poemas escogidos, Madrid, Cátedra.

MacCarthy, Fiona (2011): The Last Pre-Raphaelite: Edward Burne-Jones and the Victorian Imagination, London, Faber \& Faber.

Meredith, Georges (2003): The Shaving of Shagpat. An Arabian Enterteinment, Pennsylvania, Pennsylvania State University.

Miquel-Baldellou, Marta (2008): "Demonising the Victorian heroine's coming-of-age in Edward Bulwer-Iytton's Lucretia and Edgar Allan Poe's women's tales”, Odisea: Revista de Estudios Ingleses, 9, 179-190.

Nead, Lynda (1988): Myths of Sexuality: Representations of Women in Victorian Britain, Oxford, Blackwell.

Perrault, Charles (2016): Cuentos completos, Madrid, Alianza Editorial.

Prettejohn, Elizabeth (2000): The Art of the Pre-Raphaelites, Princeton, Princeton University Press.

Ribeyrol, Charlotte (2014): "Pintores y poetas: correspondencias victorianas", en Alma-Tadema y la pintura victoriana en la colección Pérez-Simón, Vv.aa., Madrid, Fundación Colección Thyssen-Bornemisza, 25-34.

Rosenfeld, Jason (2012): John Everett Millais, London, Phaidon Press.

Stott, Rebecca (1992): The Fabrication of the Late-Victorian Femme Fatale: the Kiss of Death, Basingstoke, Macmillan. 
Tennyson, Alfred (2002): La dama de Shalott y otros poemas, Valencia, Pre-textos.

VV.AA. (2009): La Bella Durmiente: Pintura victoriana del Museo de Arte de Ponce, Madrid, Ediciones El Viso.

Walser, Robert (1997): Poemas-Blancanieves, Barcelona, Icaria Editorial.

Walser, Robert (2015): Fairy Tales, New York, New Directions.

Werner, Marcia (2005): Pre-Raphaelite Painting and Nineteenth-Century Realism, Cambridge, Cambridge University Press.

Wood, Christopher (1983): Olympian Dreamers: Victorian Classical Painters 1860- 1914, London, Constable.

Wood, Christopher (1999): Burne-Jones: the life and works of Sir Edward Burne-Jones (1833-1898), London, Phoenix Illustrated.

Zipes, Jack (2011): The Enchanted Screen: The Unknown History of Fairy-Tale Films, New York, Routledge. 